${ }^{1}$ Department of Ophthalmology, American University of Beirut, POB

113-6044, Beirut, Lebanon

${ }^{2}$ Department of Ophthalmology, University of Texas Southwestern,

Dallas, TX, USA

${ }^{3}$ Department of Ophthalmology, Wills Eye Hospital, Philadelphia, PA, USA

${ }^{4}$ Department of Anesthesiology, American University of Beirut, Beirut, Lebanon

${ }^{5}$ Department of Epidemiology and Population Health, American University of Beirut, Beirut, Lebanon

${ }^{6}$ Department of Internal Medicine, American University of Beirut, Beirut, Lebanon

${ }^{7}$ Department of Health Management and Policy, American University of Beirut, Beirut, Lebanon

${ }^{8}$ Department of Surgery, American University of Beirut, Beirut, Lebanon

Correspondence:

AM Mansour,

Tel: + 9611374625 ;

Fax: + 9611744464

E-mail:dr.ahmad@

cyberia.net.lb

Received: 6 February 2005 Accepted in revised form: 12 April 2005

Published online: 8 July 2005

\section{Anterior ischaemic optic neuropathy after coronary artery bypass graft: the role of anaemia in diabetics}

\author{
Abstract \\ Purpose To ascertain factors associated \\ with anterior ischaemic optic neuropathy \\ (AION) following coronary artery \\ bypass graft (CABG) in a Lebanese \\ population. \\ Methods A retrospective chart review of \\ consecutive CABG performed over a 5-year \\ period (1995-1999) in one medical centre. \\ A comparison of clinical characteristics was \\ carried out between AION cases and subjects \\ free from AION. The variables analysed \\ included history of diabetes as well as \\ preoperative, intraoperative, or postoperative \\ values of haematocrit, blood sugar, \\ oxygen saturation, and arterial blood \\ pressure.
}

Results A total of 1594 persons were included. Three subjects experienced acute visual loss from AION following CABG, all had diabetes mellitus, and two suffered from severe postoperative anaemia. Among diabetics $(n=484)$, the risk of AION was significantly higher in subjects with postoperative haematocrit falling below $22(28.6 \%)$ than the rest $(0.21 \%)$ $(P=0.001)$. Blood transfusion was given in two subjects with prompt visual recovery.

Conclusions Severe anaemia in patients undergoing $C A B G$ appears to be a risk factor for AION, especially in diabetics, and needs prompt correction to prevent or reverse the ischaemic ocular events.

Eye (2006) 20, 706-711. doi:10.1038/sj.eye.6701979; published online 8 July 2005

Keywords: anaemia; anterior ischaemic optic neuropathy; blood transfusion; coronary artery bypass graft; diabetes mellitus
AM Mansour ${ }^{1}$, ST Awwad ${ }^{2}$, DM Najjar ${ }^{3}$, AN Sibai ${ }^{4}$, AM Sibai ${ }^{5}$, WA Medawar ${ }^{6}$, IH Hamade', RS Haddad ${ }^{1}$, KM Kassak ${ }^{7}$ and MY Obeid ${ }^{8}$

\section{Introduction}

Anterior ischaemic optic neuropathy (AION) is a rare event with an incidence of around $0.01 \%$ in the general population. ${ }^{1}$ Although uncommon, alterations in vision and blindness after anaesthesia for major surgical procedures are well documented, with an incidence varying between 0.05 and $1 \% .^{2}$ Prior to the start of this investigation, one of us (AMM) examined over a period of 9 years six consecutive subjects with AION after coronary artery bypass graft (CABG), and all were diabetic. This prompted us to examine variables that render diabetics undergoing $\mathrm{CABG}$ prone for this complication. In this paper, we report the clinical characteristics of subjects with AION following CABG performed over a 5-year period, and compare them to subjects free from AION during the same period, as well as to cases reported in the literature. ${ }^{3-19}$ A better understanding of the factors associated with postoperative AION can aid in the development of preventive and therapeutic measures.

\section{Materials and methods}

Excluding cases with combined valve disease or reoperations, a thorough chart review of the computer files of all CABG patients whose records were electronically accessible in the CABG Registry of the American University of Beirut from 1995 to 1999 was conducted. The patients' names were kept anonymous and the Ethics Committee approval was waived. Age, gender, and systemic diseases including adultonset diabetes mellitus, systemic hypertension (systolic above $150 \mathrm{mmHg}$ or diastolic above $90 \mathrm{mmHg}$ ), and carotid artery disease were recorded. We also extracted variables such as preoperative, intraoperative, and (first 2 days) 
Table 1 Comparison of the clinical parameters between the three AION cases with those free from AION among patients undergoing CABG at the American University Hospital (1995-1999) (values between parentheses represent SEM)

\begin{tabular}{|c|c|c|c|c|c|}
\hline & Non-AION patients & AION-1 & AION-2 & AION-3 & $\begin{array}{l}\text { Series of } \\
\text { AION cases }\end{array}$ \\
\hline Number of subjects & 1591 & 1 & 1 & 1 & 3 \\
\hline Sex (\% male) & $84.4 \%$ & Male & Male & Female & $66.7 \%$ \\
\hline Mean age & $60.9(0.3)$ & 70 & 69 & 51 & 63.3 \\
\hline Systemic hypertension & $39.4 \%$ & No & No & No & $0 \%$ \\
\hline Diabetes mellitus & $30.2 \%$ & Yes & Yes & Yes & $100 \%$ \\
\hline Preoperative blood pressure $(\mathrm{mmHg})$ & $119.4(0.4)$ & 110 & 130 & 110 & 116.7 \\
\hline Intraoperative blood pressure $(\mathrm{mmHg})$ & $91.9(1.2)$ & 100 & 105 & 95 & 100 \\
\hline Postoperative blood pressure (mmHg) & $116.5(0.8)$ & 140 & 130 & 110 & 126.7 \\
\hline $\begin{array}{l}\text { Lowest intraoperative systolic blood pressure } \\
<100 \mathrm{mmHg}\end{array}$ & $\begin{array}{c}4.2 \%(\text { median } \\
\text { duration = } 15 \mathrm{~min})\end{array}$ & No & No & No & $0 \%$ \\
\hline Postoperative haematocrit & $29.3(0.1)$ & 19 & 20 & 26 & 21.7 \\
\hline Intra- or postoperative haematocrit $<22$ & $1.4 \%$ & Yes & Yes & No & $66.7 \%$ \\
\hline Preoperative oxygen saturation & $94.7(0.3)$ & 97.8 & 99 & 93 & 96.6 \\
\hline Postoperative oxygen saturation & $95.5(0.2)$ & 98.8 & 97 & 96 & 97.3 \\
\hline Operating time & $197 \min (0.7 \mathrm{~min})$ & $255 \mathrm{~min}$ & $155 \mathrm{~min}$ & $245 \mathrm{~min}$ & $218 \mathrm{~min}$ \\
\hline Aortic clamping time & $40 \min (0.4 \mathrm{~min})$ & $44 \mathrm{~min}$ & $30 \mathrm{~min}$ & $43 \mathrm{~min}$ & $39 \mathrm{~min}$ \\
\hline Bypass time & $67 \min (0.6 \mathrm{~min})$ & $68 \mathrm{~min}$ & $47 \mathrm{~min}$ & $73 \mathrm{~min}$ & $62.7 \mathrm{~min}$ \\
\hline Bilateral AION & $0 \%$ & No & Yes & No & $33.3 \%$ \\
\hline $\begin{array}{l}\text { Initial postoperative best-corrected visual } \\
\text { acuity (median) }\end{array}$ & NA & $6 / 12 \mathrm{OD}$ & CF OU & $6 / 24 \mathrm{OD}$ & $6 / 60$ \\
\hline $\begin{array}{l}\text { Final postoperative best-corrected visual acuity } \\
\text { (median) }\end{array}$ & NA & $6 / 7.5^{\mathrm{a}} \mathrm{OD}$ & $\begin{array}{l}6 / 15 \mathrm{OD}^{\mathrm{b}} 6 / 30 \\
\mathrm{OS}^{\mathrm{b}}\end{array}$ & 6/6 OD & $6 / 15$ \\
\hline Altitudinal visual field defect & NA & Yes & Yes & Yes $^{c}$ & $66.7 \%$ \\
\hline
\end{tabular}

$\mathrm{OD}=$ right eye; $\mathrm{OS}=$ left eye; $\mathrm{OU}=$ both eyes; $\mathrm{CF}=$ counting fingers; $\mathrm{NA}=$ not assessed.

aPrompt subjective visual improvement after transfusion of $4 \mathrm{U}$ of packed cells.

brompt subjective visual improvement after transfusion of $5 \mathrm{U}$ of packed cells.

cDiffuse depression of visual field besides an altitudinal defect.

postoperative values of the following: haematocrit, blood sugar, oxygen saturation, and arterial blood pressure. Ocular and neurological exams (including carotid duplex scan) were also retrieved. The review identified a total of three cases of AION (Table 1). AION is hereby defined as disc swelling associated with visual loss, visual field defect, and absence of telangiectatic disc capillaries (seen in diabetic papillopathy).

Under general anaesthesia, cardiopulmonary bypass was initiated using a Bentley Univox membrane oxygenator, Bentley arterial filter $(40 \mu \mathrm{m})$, and Bentley cardiotomy reservoir $(18 \mu \mathrm{m})$ (Baxter Health Care, Compton, UK). The patients were perfused with a roller pump (Sarns 7000, Ann Arbor, MI, USA) at a flow rate of $2.41 \mathrm{~min}^{-1} \mathrm{~m}^{-2}$ using continuous nonpulsatile flow. The circuit, including the membrane oxygenator, filter, reservoir, and lines was not coated. Moderate systemic hypothermia was induced to approximately $28^{\circ} \mathrm{C}$ measured by a venous temperature probe. A series of activated clotting time was performed at baseline, postheparin to insure an activated clotting time above $480 \mathrm{~s}$, and postprotamine reversal. Arterial blood gases were measured at baseline, after connecting the patient to the respirator, and every $15 \mathrm{~min}$ during cardiopulmonary bypass utilizing alpha-stat method. During cardiopulmonary bypass, blood glucose levels were maintained at less than $180 \mathrm{mg} / \mathrm{dl}$ and hematocrit between 25 and 30\%. During the first $48 \mathrm{~h}$ postoperatively, blood pressure and oxygen saturation were monitored continuously and recorded hourly, while hematocrit was measured every $12 \mathrm{~h}$.

Statistical analysis was conducted using Fisher's exact test, and a $P$-value $<0.05$ was considered significant.

\section{Results}

During the study period, 1594 white subjects with a mean age of 60.9 years (SEM 0.26 years) underwent CABG. In all, 49 subjects underwent emergency CABG, while the rest underwent scheduled CABG (including the three subjects with AION). The majority consisted of males $(81.4 \%)$. Systemic hypertension was present in 627 subjects $(39.3 \%)$, and diabetes mellitus in $484(30.4 \%)$ (Table 1). Carotid duplex scan was performed in 45 subjects and was 'positive' (more than 70\% stenosis) in 10 subjects. Intraoperative systolic blood pressure dipped below $100 \mathrm{mmHg}$ in 67 subjects (4.2\%). Mean blood pressure was $119.4 \mathrm{mmHg}(0.4 \mathrm{mmHg})$ preoperatively, 
$91.9 \mathrm{mmHg}(1.2 \mathrm{mmHg})$ intraoperatively, and $116.5 \mathrm{mmHg}(0.8 \mathrm{mmHg}) 1$ day postoperatively. Mean haematocrit was 40.5 (0.1) preoperatively, 30.1 (0.1) on the first postoperative day, and 29.3 (0.1) on the second postoperative day. Haematocrit (intraoperatively and first 2 days postoperatively) fell below 22 in 30 subjects, seven of them having diabetes mellitus. Mean arterial oxygen saturation was $94.7 \%(0.3 \%)$ preoperatively and $95.9 \%(0.2 \%)$ postoperatively. Total operating room time, clamping of aorta duration, and bypass time were, respectively, $3.28 \mathrm{~h}(0.7 \mathrm{~min}), 40 \mathrm{~min}(0.4 \mathrm{~min})$, and $67 \mathrm{~min}$ (0.6 min). Death occurred in seven subjects intraoperatively or in the coronary care unit.

Ocular symptoms occurred in eight subjects. Visual loss was the major complaint in seven subjects $(0.4 \%)$ and resulted from unilateral AION in two patients, or from diabetic retinopathy, glaucoma, age-related macular degeneration, retinal artery embolus, and negative eye exam (transient visual blur of $24 \mathrm{~h}$ on the second day after CABG in a nondiabetic subject with transient postCABG cerebral nervous system dysfunction) in one patient each. Two subjects complained of visual field, one having retinal artery embolus, and one having homonymous haemianopia from bilateral AION (the patient was severely bothered by the field defect and to a much lesser degree by the visual loss). Ophthalmic consultation was not required in 1575 subjects (98.8\%).

Among AION subjects, the onset of visual symptoms was 1-3 days after CABG. Visual fields revealed altitudinal defects in all AION patients. Disc oedema involved the right eye in two patients (both had afferent pupillary defect), and both eyes in one patient. Two patients received blood transfusion ( 4 or $5 \mathrm{U}$ of packed red blood cells) and reported subjective improvement of vision within $24 \mathrm{~h}$ of the blood transfusion. Disc oedema was observed to decrease gradually over a period of 5 days in both patients. There was resolution of disc oedema and return of vision by the fifth day after infusion in both subjects. In the bilateral AION, the right eye improved from finger counting to 6/15 2 days after transfusion, while the left eye improved from finger counting to 6/30 5 days after transfusion. At 5 days after blood transfusion in the unilateral AION, visual acuity improved from $6 / 12$ to $6 / 7.5$ with resolution of the afferent pupillary defect.

None of the three cases with AION suffered systemic hypotension intraoperatively or postoperatively. All had diabetes mellitus, and two suffered from severe postoperative anaemia. Comparison of the three subjects with AION (mean haematocrit 21.7) and the rest (1591 subjects) (mean haematocrit 29.3) highlighted the role of anaemia among diabetics in the risk of occurrence of AION. Among diabetics $(n=484)$, the risk of AION was significantly higher in subjects with intraoperative or first 2 days postoperatively haematocrit falling below 22 $(28.6 \%)$ than the rest $(0.21 \%)(P=0.001)$ (Table 2). Also, the magnitude of the association between low haematocrit and AION was stronger among diabetics than the total study population (risk ratio 136 vs 104) (Table 3).

\section{Discussion}

Findings of the present study underscore the role of anaemia in the occurrence of AION among diabetic patients undergoing CABG. As a result of increased atherosclerosis in diabetes mellitus, ${ }^{20}$ a large percentage of patients undergoing CABG are diabetic. Diabetics have a higher perioperative mortality and morbidity following CABG with twice the mortality of nondiabetics, a greater number of sternotomy complications, and a greater number of renal insufficiency than nondiabetics. ${ }^{20}$

AION develops after a decrease in the oxygen supply to the optic nerve head anterior to the lamina cribrosa, a watershed area mainly supplied by the posterior ciliary arteries. It is conceivable that interruption or decrease in the vascular supply to the optic nerve head via prolonged hypotension, severe anaemia, vasospasm, or a combination thereof (precipitating event), can lead to optic nerve ischaemia especially in the context of either a systemic disease causing arteriosclerosis of small vessels

Table 2 Distribution of patients undergoing CABG (1995-1999) by haematocrit level and diabetes status (figures in parenthesis represent row percentages within each stratum)

\begin{tabular}{|c|c|c|c|c|c|c|c|}
\hline \multirow[t]{2}{*}{ Haematocrit falling below 22} & \multicolumn{2}{|c|}{ Diabetics } & \multicolumn{2}{|c|}{ Nondiabetics } & \multicolumn{2}{|c|}{ All subjects } & \multirow[t]{2}{*}{ Total } \\
\hline & AION present & AION absent & AION present & AION absent & AION present & AION absent & \\
\hline Yes & $2(28.6 \%)$ & 5 & $0(0 \%)$ & 23 & $2(6.7 \%)$ & 28 & 30 \\
\hline No & $1(0.21 \%)$ & 476 & $0(0 \%)$ & 1087 & $1(0.06 \%)$ & 1563 & 1564 \\
\hline Total & 3 & 481 & 0 & 1110 & 3 & 1591 & 1594 \\
\hline Risk ratio ${ }^{a}$ & \multirow{2}{*}{\multicolumn{2}{|c|}{136}} & & & \multicolumn{2}{|c|}{104} & \\
\hline$P$-value (Fisher's exact test) & & & & & \multicolumn{2}{|c|}{0.001} & \\
\hline
\end{tabular}

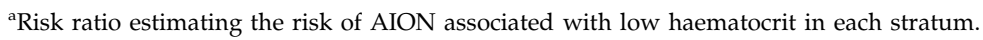


Table 3 Literature review of 35 AION cases following isolated (without valve disease) on-pump CABG

\begin{tabular}{|c|c|c|c|c|c|}
\hline Author & Age (mean) & Diabetes & Haematocrit (mean $\pm S D)$ & Eye & Final visual acuity - median \\
\hline \multirow[t]{3}{*}{ Alpert (three cases) } & 54 & No & 28.7 & OD & $6 / 9$ \\
\hline & 54 & No & 27.4 & OS & $6 / 12$ \\
\hline & 63 & Yes & 24.7 & OU & NM \\
\hline Tice (three cases) & NM & NM & $<20$ & NM & NM \\
\hline Rizzo & 46 & Yes & 26.0 & OU & NLP \\
\hline \multirow[t]{2}{*}{ Jaben (two cases) } & 56 & No & 23.4 & OU & $6 / 66 / 9$ \\
\hline & 44 & No & 20.4 & OS & $6 / 9$ \\
\hline Moster & 70 & Yes & 20.4 & OD & $6 / 7.5$ \\
\hline \multirow[t]{3}{*}{ Brown (three cases) } & 68 & Yes & 18.0 & OU & $6 / 306 / 24$ \\
\hline & 74 & No & 20.4 & OD & $6 / 7.5$ \\
\hline & 81 & No & 18.4 & OS & $6 / 60$ \\
\hline Lund & 74 & No & 21.0 & OS & NLP \\
\hline \multirow[t]{3}{*}{ Shapira (five cases) } & (64) & $25 \%+$ & $(18.4 \pm 1.8)$ & OU 3 & $\mathrm{NA}^{\mathrm{a}}$ \\
\hline & & & & OD 1 & \\
\hline & & & & OS 1 & \\
\hline \multirow[t]{2}{*}{ Busch (two cases) } & 71 & Yes & 21.2 & OU & NLP HM \\
\hline & 58 & Yes & 17.0 & OU & CF 6/30 \\
\hline Nuttall (14 cases) & (65) & $29 \%^{\mathrm{b}}$ & $(23.1 \pm 3.3)^{\mathrm{b}}$ & OU $53 \%^{\mathrm{b}}$ & $\mathrm{CF}^{\mathrm{b}}$ \\
\hline Total $^{\mathrm{c}}$ (35 cases) & (60) & $34.4 \%$ & $(21.7)$ & $50 \%$ OU & $6 / 30$ \\
\hline
\end{tabular}

$\mathrm{NM}=$ not mentioned; $\mathrm{NA}=$ not assessed; $\mathrm{OD}=$ right eye; $\mathrm{OS}=$ left eye; $\mathrm{OU}=$ both eyes; $\mathrm{CF}=$ counting fingers; $\mathrm{HM}=$ hand motion; $\mathrm{NLP}=$ no light perception.

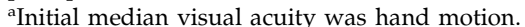

${ }^{\mathrm{b}}$ Cases with valve defect were omitted from the series, and the values listed here represent the original percentage for the whole series.

'Some clinical variables were not available in some series.

(diabetes mellitus) and/or local predisposing factor (small disc, narrow scleral canal, small optic cup). It could be argued that diabetics are more prone for postCABG AION because of small optic discs. However, Konigsreuther and Jonas ${ }^{21}$ found similar disc morphology in comparing diabetics and nondiabetic subjects.

AION is multifactorial: small optic disc size, ${ }^{22}$ systemic vascular disease, systemic hypotension including nocturnal hypotension, anaemia, ${ }^{23}$ and a hypercoagulable state. The three patients with AION in the present study had a small optic disc, diabetes mellitus, and significant postoperative blood loss. Diabetes mellitus is generally accepted as a risk factor for AION. ${ }^{24}$ Diabetics appear particularly susceptible for this ischaemic event especially if the haematocrit drops below 22. In the present study, out of 30 subjects whose haematocrit fell below 22, seven were diabetic, two of whom (two out of seven or 29\%) developed AION. Therefore, diabetics with low haematocrit appear at a high risk for AION. Prompt correction of anaemia led to visual improvement in two out of two subjects who received homologous blood transfusion. This is in concordance with the literature showing visual improvement following prompt correction of hypotension or anaemia in AION patients. ${ }^{25,26}$

Table 3 reproduces findings from the literature on reported ION cases (35 cases) and presents their clinical characteristics in terms of presence of diabetes, mean haematocrit, and visual acuity. The comparison between the reported literature cases of AION (35 cases, Table 3) with subjects without AION in our study (1591 subjects, Table 2) provides further evidence for the role of anaemia in AION, where mean haematocrit was lower in reported AION case-series (21.7 vs 29.3) and the proportion of subjects having postoperative haematocrit $<22$ was much higher (60 vs 1.4\%). Nuttall et al ${ }^{11}$ identified AION cases after CABG with or without valve repair between 1976 and 1994 at the Mayo Clinic in Rochester, and selected for each AION case two controls. The authors ${ }^{11}$ found postoperative anaemia to be significantly associated with AION after CABG. In another study, ${ }^{15}$ prolonged cardiopulmonary bypass time, low postoperative haematocrit, excessive perioperative body weight gain, and use of epinephrine or amrinone were also found to be associated with AION. Moster, ${ }^{10}$ Jaben, ${ }^{8}$ Brown, ${ }^{4}$ and Jarrell ${ }^{27}$ found postoperative anaemia to be a predisposing cause for AION. Anaemia can conceivably result in a reduction of oxygen-carrying capacity and subsequent ischaemia in the watershed zones. Pre-existent small vessel disease from diabetes mellitus can predispose for ischaemia in the watershed zones (posterior ciliary arteries) leading to AION via decreased vascular perfusion and loss of autoregulation (inability to increase perfusion in response to severe anaemia).

AION can follow any major surgical procedure specifically CABG and spine surgery. Prolonged surgery 
in the prone position ${ }^{28}$ is one risk factor for AION after spine surgery. Katz et al ${ }^{29}$ described four cases of AION after lumbar spine surgery and identified three risk factors: prolonged intraoperative hypotension, severe anaemia, and arteriosclerosis (diabetes). Visual loss was often irreversible following AION after spine surgery, ${ }^{28}$ possibly because AION was not recognized early and was not treated promptly ${ }^{26} \mathrm{Lee}^{30}$ and Stevens $e a^{26}$ found that early aggressive correction of anaemia and systemic hypotension allowed reversal of ophthalmic complications of spine surgery with visual recovery.

A large number of cardiothoracic surgeons use aggressive haemodilution for CABG with a haematocrit of $17-24 \%$ as ideal postoperatively. ${ }^{31}$ One argument for haemodilution is the reduced viscosity resulting in improved blood circulation. ${ }^{31}$ However, haemodilution results in worse cognitive outcome from decreased oxygen carrying capacity and relative hypoxia (a similar mechanism happening in the optic nerve). Jonas ${ }^{31}$ considered the lowest acceptable haematocrit level in adult CABG to be $25 \%$, and we would propose a higher level in diabetics (25-30\%). The anaemia and relative hypoxia aggravate tissue injury in multiple organ systems and accelerate small vessel disease in diabetic patients. ${ }^{32}$

AION in diabetics is easily differentiated from diabetic papillopathy and from arteritic ischaemic optic neuropathy.

The current study has several limitations: small size of AION patients preventing further statistical analyses, retrospective nature, and nonsystematic ocular examination of the patients. Findings of the present study suggest that altering the postoperative management of severely anaemic diabetic subjects by replacing blood loss can reverse some of the visual loss from AION. It could be argued that part of the visual recovery after blood transfusion is related to reversal of systemic hypotension, yet the three AION patients did not experience detectable systemic hypotension postoperatively. Larger studies are needed to confirm that AION in diabetics is a factor that promotes blood transfusion. We did not place a cutoff for blood transfusion after $C A B G$, but suggest that reversal of anaemia in AION is beneficial and prevention of severe anaemia in diabetics may be a safe strategy to follow. We recommend that anaemia therapy be included in the current management of patients with diabetes mellitus ${ }^{32}$ and AION after CABG.

\section{Acknowledgements}

The authors have no financial interest in any product mentioned in the study. Presented in part at the 2001 meeting of the American Academy of Ophthalmology, New Orleans, LA, USA.

\section{References}

1 Hattenhauer MG, Leavitt JA, Hodge DO, Grill R, Gray DT. Incidence of nonarteritic anterior ischemic optic neuropathy. Am J Ophthalmol 1997; 123: 103-107.

2 Williams EL. Postoperative blindness. Anesthesiol Clin North America 2002; 20: 605-622.

3 Alpert JN, Pena Y, Leachman DR. Anterior ischemic optic neuropathy after coronary bypass surgery. Tex Med 1987; 83: $45-47$.

4 Brown RH, Schauble JF, Miller NR. Anemia and hypotension as contributors to perioperative loss of vision. Anesthesiology 1994; 80: 222-226.

5 Busch T, Sirbu H, Aleksic I, Stamm C, Zenker D, Dalichau H. Anterior ischemic optic neuropathy: a complication after extracorporal circulation. Ann Thorac Cardiovasc Surg 1998; 4: 354-358.

6 Busgen P, Framme C, Hoerauf H. Beidseitige Visusminderung nach aortokoronarer Bypassoperation. Ophthalmologe 1999; 96: 834-835.

7 Lund PE, Madsen K. Bilateral blindness after cardiopulmonary bypass. J Cardiothorac Vasc Anesth 1994; 8: 448-450.

8 Jaben SL, Glaser JS, Daily M. Ischemic optic neuropathy following general surgical procedures. J Clin Neuroophthalmol 1983; 3: 239-244.

9 Larkin DFP, Wood AE, Neligan M, Eustace P. Ischaemic optic neuropathy complicating cardiopulmonary bypass. Brit J Ophthalmol 1987; 71: 344-347.

10 Moster ML. Visual loss after coronary artery bypass surgery. Surv Ophthalmol 1998; 42: 453-457.

11 Nuttall GA, Garrity JA, Derani JA, Abel MD, Schroeder DR, Mullany CJ. Risk factors for ischemic optic neuropathy after cardiopulmonary bypass: a matched case/control study. Anesth Analg 2001; 93: 1410-1416.

12 Rizzo III JF, Lessell S. Posterior ischemic optic neuropathy during general surgery. Am J Ophthalmol 1987; 103: 808-811.

13 Sha'aban RI, Asfour WM. Visual loss after coronary artery bypass surgery. Saudi Med J 2000; 21: 90-92.

14 Shahian DM, Speert PK. Symptomatic visual deficits after open heart operations. Ann Thorac Surg 1989; 48: 275-279.

15 Shapira OM, Kimmel WA, Lindsey PS, Shahian DM. Anterior ischemic optic neuropathy after open heart operations. Ann Thorac Surg 1996; 61: 660-666.

16 Spoor TC, Wilkinson MJ, Ramocki JM. Optic nerve sheath decompression for the treatment of progressive nonarteritic ischemic optic neuropathy. Am J Ophthalmol 1991; 111: 724-728.

17 Sweeney PJ, Breuer AC, Selhorst JB, Waybright EA, Furlan AJ, Lederman RJ et al. Ischemic optic neuropathy: a complication of cardiopulmonary bypass surgery. Neurology 1982; 32: 560-562.

18 Tice DA. Ischemic optic neuropathy and cardiac surgery (Correspondence). Ann Thorac Surg 1987; 44: 677.

19 Tomsak RL. Ischemic optic neuropathy associated with retinal embolism. Am J Ophthalmol 1985; 99: 590-592. 
20 Barzilay JI, Kronmal RA, Bittner V, Eaker E, Evans C, Foster ED. Coronary artery disease and coronary artery bypass grafting in diabetic patients aged $>65$ years (Report from the Coronary Artery Surgery Study [CASS] Registry). Am J Cardiol 1994; 74: 334-339.

21 Konigsreuther KA, Jonas JB. Optic disc morphology in diabetes mellitus. Graefes Arch Clin Exp Ophthalmol 1995; 233: 200-204.

22 Mansour AM, Shoch D, Logani S. Optic disc size in anterior ischemic optic neuropathy. Am J Ophthalmol 1988; 106: 587-589.

23 Mansour AM, Salti H, Han DP et al. Ocular findings in aplastic anemia. Ophthalmologica 2000; 214: 300-402.

24 Hayreh SS, Joos KM, Podhajsky PA, Long CR. Systemic diseases associated with nonarteritic anterior ischemic optic neuropathy. Am J Ophthalmol 1994; 118: 766-780.

25 Connolly SE, Gordon KB, Horton JC. Salvage of vision after hypotension-induced ischemic optic neuropathy. Am J Ophthalmol 1994; 117: 235-242.
26 Stevens WR, Glazer PA, Kelley SD, Lietman TM, Bradford DS. Ophthalmic complications after spine surgery. Spine 1997; 22: 1319-1324.

27 Jarrell III RL, Jones WL. Juxtapapillary nerve fiber layer infarction as a complication of coronary artery bypass surgery. J Am Optom Assoc 1998; 69: 759-765.

28 Myers MA, Hamilton SR, Bogosian AJ, Smith CH, Wagner TA. Visual loss as a complication of spine surgery. A review of 37 cases. Spine 1997; 22: 1325-1329.

29 Katz DM, Trobe JD, Cornblath WT, Kline LB. Ischemic optic neuropathy after lumbar spine surgery. Arch Ophthalmol 1994; 112: 925-931.

30 Lee AG. Ischemic optic neuropathy following lumbar spine surgery. Case report. J Neurosurg 1995; 83: 348-349.

31 Jonas RA. Optimal hematocrit for adult cardiopulmonary bypass (letter). J Cardiothorac Vas Anesth 2001; 15: 672.

32 Sinclair SH, DelVecchio C, Levin A. Treatment of anemia in the diabetic patient with retinopathy and kidney disease. Am J Ophthalmol 2003; 135: 740-743. 